\title{
The Manifestations and Characteristics of School Bullying in China: An Analysis Based on 50 Typical Cases Reported on the Internet
}

\author{
Ruohan $\mathrm{Li}^{1} \& \mathrm{Na} \mathrm{Gao}{ }^{1}$ \\ ${ }^{1}$ National University of Defense Technology, Changsha, China \\ Correspondence: Ruohan Li, Associate Professor, National University of Defense Technology, Changsha 430072, \\ China. E-mail: j.liruohan@hotmail.com
}

Received: March 10, 2021

Accepted: March 26, 2021

Online Published: April 6, 2021

doi:10.5430/irhe.v5n4p36

URL: https://doi.org/10.5430/irhe.v5n4p36

\begin{abstract}
This is a case study of school bullying in China. There are two main types of school bullying: mental bullying and physical bullying which is the main form of school bullying in China. It is worth noting that the frequency of sexual bullying and derivative behaviors of school bullying are in increasing now. School bullying is often a repetitive and long-term behavior and often committed by multiple people. The study shows that high school is the main place of school bullying in China and the frictions of daily life is the main cause of school bullying. The study also shows that, compared with the opposite sex, bullying behaviors between the same sex occur more frequently, and girl students are more likely to be the victims of school bullying.
\end{abstract}

Keywords: school bullying, physical bullying, mental bullying

\section{Introduction}

In recent years, there are many reports about school bullying behaviors in China. Some of these school bullying behaviors are very cruel, which has aroused great concern of public opinion. (Li, M., 2020, p. 133) From the existing research, many researchers focus on the personal and social factors leading to school bullying and the way to prevent or eliminate school bullying. However, the main problem of this research approach is that researchers pay more attention to the causes of school bullying but ignore its own characteristics as a social phenomenon. It's just like a doctor only pay attention to the cause of the disease but ignoring the symptoms of it. In fact, the study of school bullying itself is also very important. But few researchers noticed this point. By analyzing the forms and characteristics of school bullying, we can have a deeper understanding of the structure of school bullying as a whole, and it is also helpful for researchers to find the real cause of bullying, and for policy makers to find a right way to prevent and eliminate school bullying.

Based on the analysis of 50 typical school bullying cases reported on the Internet from January 2019 to May 2019 in China, the paper finds that these cases of school bullying have some salient features. Personal factors, school factors, family factors, legal factors and social factors, which are jointly giving birth to these school bullying. (Zhang, W., 2017, pp. 77-78) The study found that the occurrence of school bullying is not accidental. Behind one case reported, there may often exist 10 or even 20 similar bullying incidents that were not been reported by the media. The target of a school bullying is often not limited to the victim exposed in the report, and the list of victims who are not exposed may be 5-10 people. This means that there may 500 or more related cases behind the investigated 50 cases, and the actual victims of school bullying may be $250-500$ people. This number is very shocking. What's more, most of these 50 typical cases occurred in cities with relatively high level of right awareness and education, in which place the possibility of being exposed of school bullying by the media is rather higher. But this is just the tip of the iceberg. It can be imagined that school bullying which has not been reported may be more serious in remote and economically backward areas in Chinaf.

As far as personal factors are concerned, the perpetrators in these cases are mostly teenagers of the same age as the victims. These people often have poor moral quality and living habits, many of whom are lack of good family education, self-restraint ability in money. About $90 \%$ of these school bullying occurs in or near schools, which reflects the fact that these schools' inaction in preventing school bullying. Most schools choose to evade their responsibility after the case occurs, and try to transfer the responsibility to the perpetrators and their guardians. In this increasingly open and seductive era, the deterioration of social ethos and the spread of criminal subculture have 
corrupted young people's thoughts and bred the soil for school bullying. School is no longer as safe as we usually think. How to protect the students who are suffering from school bullying, how to persuade the perpetrators stop the violence, how to let the schools take their responsibility of safety, and how to eradicate the soil of campus bullying through social and legal mechanisms, all of these are urgent problems to be settled.

\section{Expression Forms of School Bullying}

School bullying refers to violence against students that occurs in public or private schools, or the way to or from school, as well as the place in the vicinity of school. (Zhao, Q., 2020, p.104) This kind of behavior infringes on the personal and property safety of the victims, destroys the public order of schools, and damages the educational environment of the society. It can be understood as a kind of individual or group abuse. (Yong, Q., 2019, p. 121) The perpetrators use force, their power and other oppressive forces to invade, bully and humiliate the victims physically or mentally. Violence and bully are main characteristics of school bullying.

There are two main types of school bullying in China: physical bullying and mental bullying. (Li, S., 2019, p. 67) Based on the analysis of 50 typical cases, it is found that there are just 4 cases involve only mental bullying, and the rest cases involve physical bullying or both. Most of school bullying cases occur in schools, and only a few cases occur near schools as follow-up events of school bullying. It is worth noting that in the network era school bullying has also given birth to some derivative harms unrelated to bullying. Such as taking bullying videos and uploading to the network. On the one hand, this kind of behavior stems from the psychology of showing off and grandstanding; on the other hand, it also aggravates the mental harm to the victims. In addition, school bullying will also lead to more serious juvenile delinquency, such as rape. Although these behaviors are carried out by teenagers, the seriousness of these behaviors makes them as special crimes.

Table 1 shows different bullying behaves of school bullying.

Table 1. Bullying behaves of school bullying in 50 typical cases

\begin{tabular}{lll}
\hline Expression form & $\begin{array}{l}\text { Number } \\
\text { cases }\end{array}$ & of Place of occurrence \\
\hline Multiple beatings & 39 & $\begin{array}{l}\text { In school or in the vicinity of } \\
\text { school }\end{array}$ \\
Beating & 3 & In school \\
Slaps & 2 & In school \\
Body abuse & 2 & In school \\
Cold violence & 3 & In classroom or in the dorm \\
Marginalizing & 2 & In the dorm \\
Stripping clothes & 1 & In the vicinity of school \\
Taking nude photos & 1 & In the vicinity of school \\
Molesting & 3 & In school \\
Sexual insulting & 4 & In school \\
Poisoning with aphrodisiac & 1 & In school \\
Taking bullying videos & 23 & In school or in the vicinity of \\
& & school \\
Robbing money & 3 & In school \\
Asking for protection fee & 1 & In school \\
Swearing with bad words & 2 & In school \\
\hline
\end{tabular}

Physical bullying is the main of school bullying. It is the behaviors of beating and corporal punishment carried out by student or student groups against other students in school, which will cause physical injury or health injury to the victims. (Shen, S-Z., 2019, p. 216) Most school bullying videos in cyberspace we could see are physical bullying videos. In a physical bullying incident, the perpetrator can establish his dignity by his barbarism actions, that makes 
the victim who is repeatedly bullied because of his failure to fight back or to refuse obedience becomes a coward. Physical bullying is the starting point for victims to suffer pains. In most cases, after physical bullying, mental bullying and other incidental bullying events follow fast.

Among the 50 typical cases, 46 cases involved physical bullying, including multiple beatings, slaps, body abuse and other forms of bullying, accounting for $92 \%$ of the total number of cases. In 23 cases of this type, the perpetrators not only carried out physical bullying, but also recorded videos and posted them to the Internet. That is to say, more than half of physical bullying incidents have derivative injuries at the same time. There are 35 cases involved physical and mental bullying at the same time, that is to say, in $70 \%$ of the cases, physical bullying and mental bullying occurred at the same time, and the victims suffered both physical and mental trauma. While only four cases involve just mental bullying. (Shown in Figure 1)

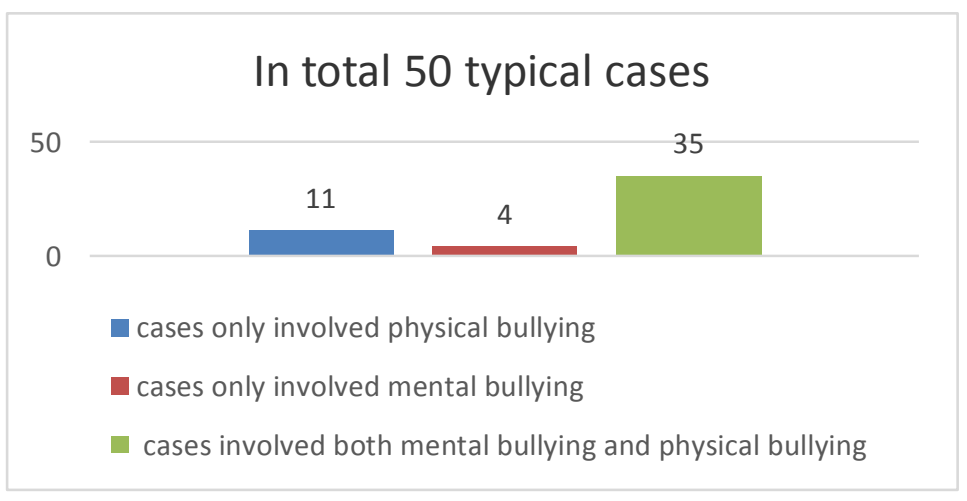

Figure 1. Number of cases involved physical bullying and mental bullying

Mental bullying is a kind of soft violence in school bullying. (Peng, C-J., Zhang, G-S., \& Chang, L-J., 2019, p. 60) It mainly uses verbal violence such as verbal abuse, slander, contempt and ridicule words, or maliciously spreads adverse rumors to invade or damage the spirit or psychology heathy of the victims. The main form of mental bullying is verbal bullying. Verbal bullying has the characteristics of timeliness and diversity. But verbal bullying itself could not suppress the resistance of the victim independently, and it is often accompanied by physical injury, such as beatings, slaps, taking bullying photos or videos. The case study shows that pure verbal bullying often occurs in the circumstances where girls are the object of infringement.

Cold violence bullying which often happens among classmates is a kind of mental bullying which is easy to be ignored. Cold violence bullying makes the victims suffer psychological harm through exclusion, isolation or other cold violence forms. Victims in the group isolation are more easily to be imposed too much mental pressure, which sometimes lead their extreme resistance behaviors, but more often they have to bear these psychological injuries alone. (Liu, D., 2018, p. 19) For example, in one case, after a female student was poisoned with aphrodisiac by the perpetrator, the girl was isolated by her classmates, and became more and more indifferent, withdrawn and silent. (Huang, H., 2018, p. 150) It is worth mentioning that cold violence bullying is particularly common in boarding schools, and it often take place in classrooms and dormitories. What's more, cold violence bullying is often a precursor of physical bullying. In case study, cold violence bullying is often accompanied by a certain degree of physical bullying. Among the 5 cases of cold violence bullying, there are 4 cases accompanied by physical bullying.

Sexual bullying is a kind of bullying with serious harm. This kind of bullying includes such bullying behaviors as striping clothes, molesting, sexual insulting, taking nude photos, poisoning with aphrodisiac. These behaviors not only violate the victims' personal rights and sexual freedom rights, but also cause serious mental harm to them. Among the 50 typical cases, 11 cases involve sexual bullying. In 9 of these cases, victims were forced to take nude photos or videos. Most victims of sexual bullying are female. Because of their shame and privacy feeling, victims usually choose to swallow their anger for a long time. Studies have shown that these sexual bullying is not a one-off behavior, but continuous ones, and most victims choose to report the matters to their school or their parents only when they can't bear the harms themselves alone. The frequency of sexual bullying in junior high school and high school is much higher than that in university campus. Because of the weakness of their right concept, these young female students are vulnerable to sexual bullying. This also reflects that our high school education has defects in sexual safety education of female students in our country. 


\section{Characteristics of School Bullying}

The school bullying in China have the following five typical characteristics.

\subsection{The Power of the Perpetrators and the Victims Is Not Balanced}

In most cases, the perpetrators use their quantity advantage or physical strength to suppress the victims. the perpetrators' power advantages include the quantity of perpetrators, the physical strength, the leadership ability or economic advantage. The power accumulated through these advantages can make them suppress the resistance of the victims or make the victims lose their will to resist. But the victim is often individual in one case, they are not strong enough to compete with the perpetrators in the fight. The unbalanced power between the perpetrators and the victims is the logical starting point of school bullying.

Case study shows that only $22 \%$ of bullying cases are committed by one person, and $78 \%$ of bullying behaviors are committed by multiple people. (Shown in Figure 2). In addition, it is worth noting that there are 35 cases in which the number of perpetrators is more than the number of victims who are often single person in one case. In a case, there was even a situation of one poor girl was beaten up by 9 junior high school students. In all these bullying cases, the perpetrators often have obvious advantages than the victims or other ordinary students. In most cases, the perpetrators all have a significant physical strength advantage than the victims. Only in a very few cases, the perpetrators are physically weak, but the leadership ability or the economic advantage of the perpetrators make them easier to form a gang by making friends with other bad guys. When a gang emerges, the physical deficiency is made up, which can make the victim dare not or unable to resist the perpetrators' bullying behaviors.

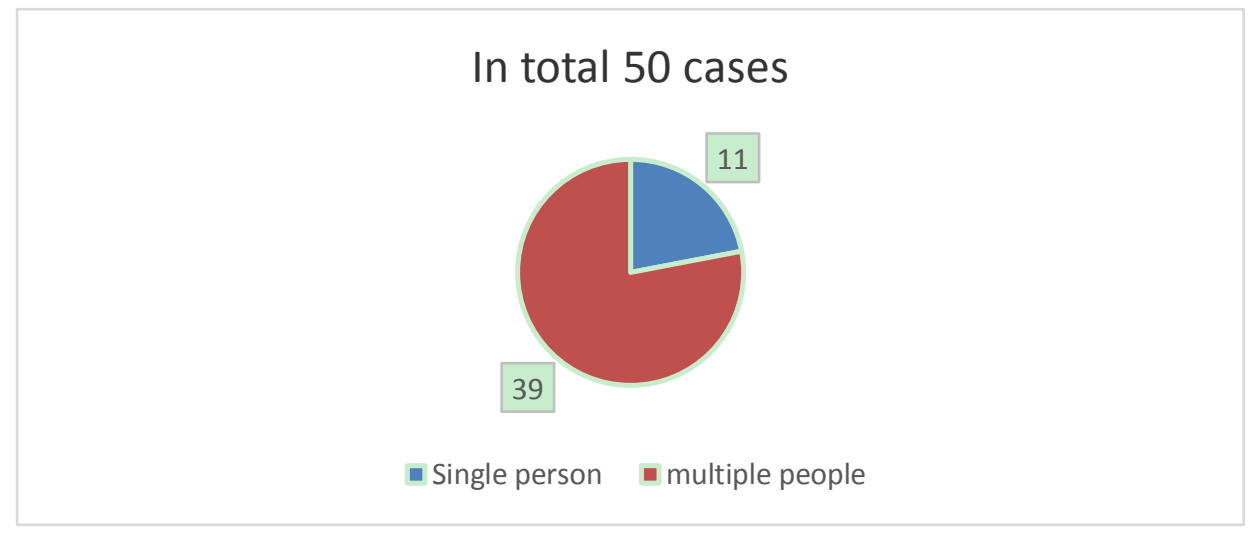

Figure 2. Structure of the perpetrators in school bullying

\subsection{School Bullying Is Often a Repetitive and Long-Term Activity}

Different from other bad behaviors, school bullying is often a repetitive and long-term behavior. 90\% of the perpetrators of school bullying have a long history of bullying. The study finds that in only 5 cases the perpetrators are the first time to commit school bullying, and $86 \%$ of the victims are repeated victims of school bullying. In 7 cases the victims denounced the perpetrators when they were injured the first time, but only three of them have suffered from only one kind of bullying behavior. (Shown in Figure 3) 


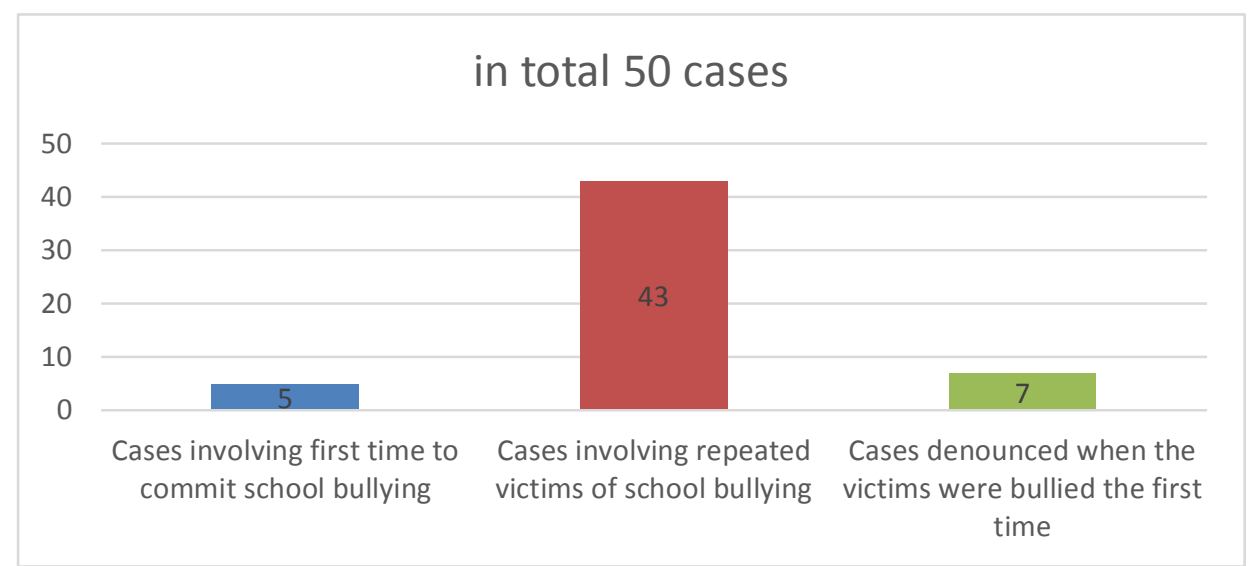

Figure 3. Case study of the 50 typical cases

School administrators and government administration agencies (with the power of administrative punishment) usually do not regard an incident of school violence as school bullying. They believe that the minor misbehavior committed by the perpetrators at one time is not serious enough for them to use the power of the government to punish the perpetrators. As an alternative, they would like to choose to persuade, educate or order the perpetrators to apologies or to correct their fault, or use other more moderate ways to solve the problem. (Teng, F., 2017, p. 77) However, this kind of ill behavior which has not been taken seriously will soon develop into a long-term school bullying, which is committed by the same perpetrators mixed with the feeling of revenge psychology and the frustration of not completely suppressing the victims. And their next bullying behavior will evolve into other worse bullying methods and will be repeatedly applied to the same victims. Research shows that in $72 \%$ of cases the perpetrators tried more than one bullying forms with the same victims after the first bullying.

\subsection{School Bullying Is Showing an Age-Younger Trend}

According to a survey conducted by the China Youth Crime Prevention Research Association, 57.95\% of the respondents who said that they had suffered from school bullying occurred in their high schools, more than $50 \%$ of them were 14 to 16 years old at that time. (Yu, Y., \& Shi, X-Q., 2019, p. 9)

Among the 50 cases cited in this paper, $78 \%$ of the cases occurred in high schools, of which $46 \%$ were in junior high schools and 32\% were in senior high schools; $12 \%$ were in universities and $10 \%$ were in vocational campuses. (Shown in Figure 4) High school has become the main place of school bullying in China. In China, the age of high school students is generally between 13 and 18 years old. At this stage, teenagers' minds are becoming more and more active, and they are prone to impulsive rebellious period. However, they lack the sense of guilt and responsibility, and their minds are not fully mature. Some daily frictions would become the main fuse leading to school violence. 


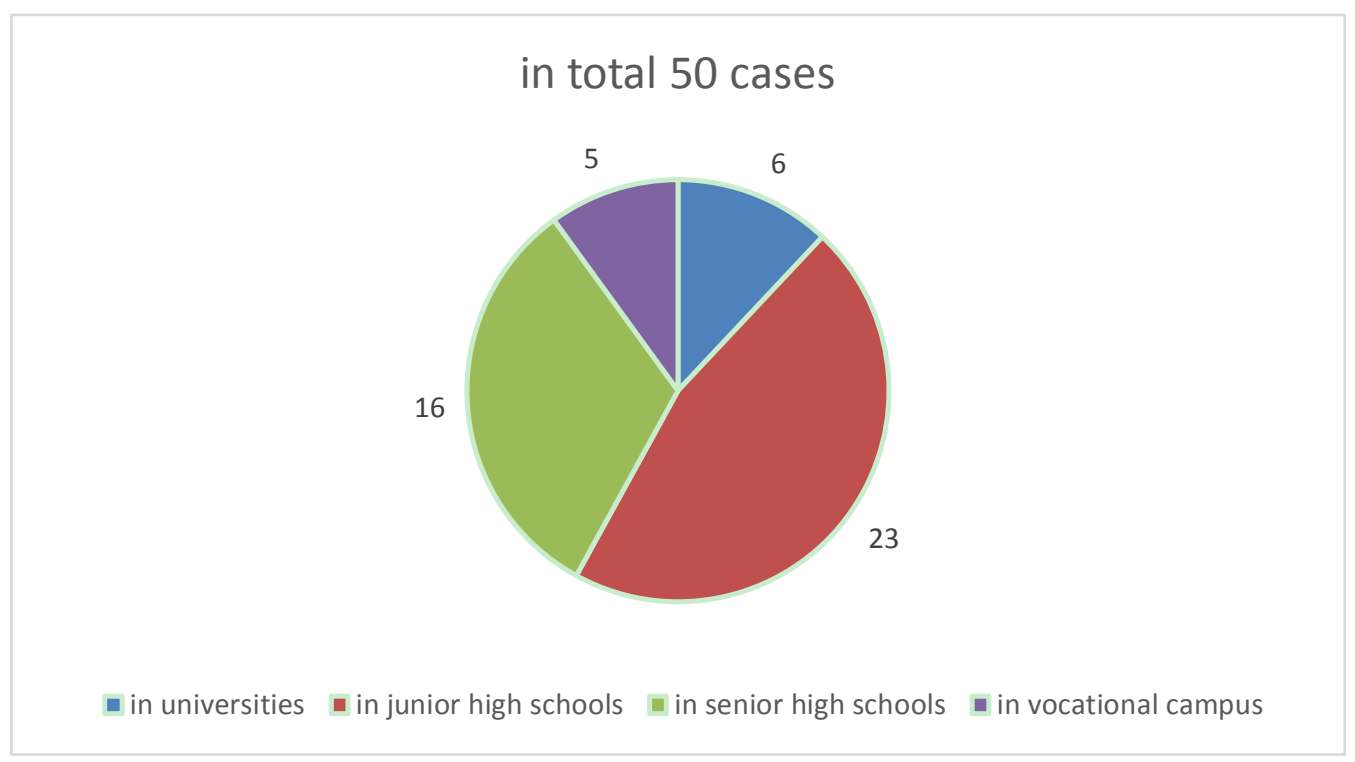

Figure 4 . The place where school bullying taking place

\subsection{School Bullying Is Mainly Caused by the Daily Disputes Among Students}

The daily disputes between students in school are often ignored. Our general cognition is that the contradictions among students, especially those among high school students, are usually small daily life frictions. Even if there are physical conflicts, they could also be seen as sudden events caused by impulsive emotion. After the impulsive emotion calms down, the students will still return to the initial peaceful state. These small frictions themselves seem not directly lead to long-term school bullying. But study finds this is not the truth. In most school bullying cases, the perpetrators' hatred and hostility to the victims are not generated out of thin air. Only a very few perpetrators will emerge long-term motives for bullying just because of the physically weakness of the victims. Most of the perpetrators had a friendly relationship, such as classmates or even acquaintances, with the victims before the occurrence of school bullying. It is the small frictions in daily life that leads to a gap between them, and makes the perpetrators have the motivation to suppress and bully the victims. In the eyes of most of the perpetrators, they are the initial victims, and bullying is only their way to fight back and revenge. Although this is more the perpetrators to find excuses for their bad behaviors, it reflects a truth that the daily life frictions that we always ignore is the direct soil for breeding campus bullying.

In the 50 typical cases, $56 \%$ of campus bullying results from daily friction; $16 \%$ from money disputes; $14 \%$ from emotional problems; $8 \%$ from extreme psychology; 6\% from other reasons. (Shown in Figure 5) In most cases, lacking of emotional control is the main cause of the first conflict, but in the subsequent development of the incidents, the perpetrators will immediately start to implement premeditated and targeted bullying activities on the victims. 


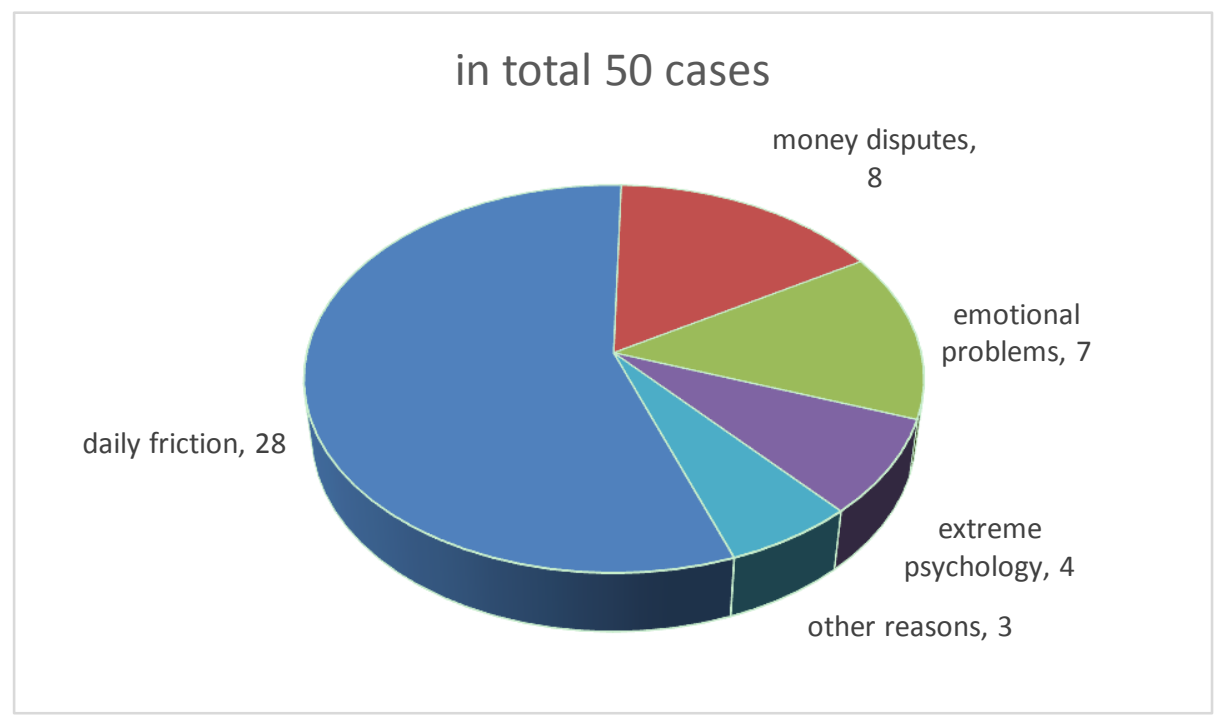

Figure 5. Causes of school bullying

\subsection{School Bullying Usually Occurs Between Students of the Same Sex}

Research shows that there are a lot of school bullying cases among students of the same sex. In 26 cases of the 50 typical cases, the perpetrators and victims are all male, accounting for 52\%; in 16 cases, the perpetrators and victims are all female, accounting for $38 \%$; in only 8 cases, the perpetrators and the victims are opposite sex, accounting for $16 \%$, in which cases all the victims are female. (Shown in Figure 6)

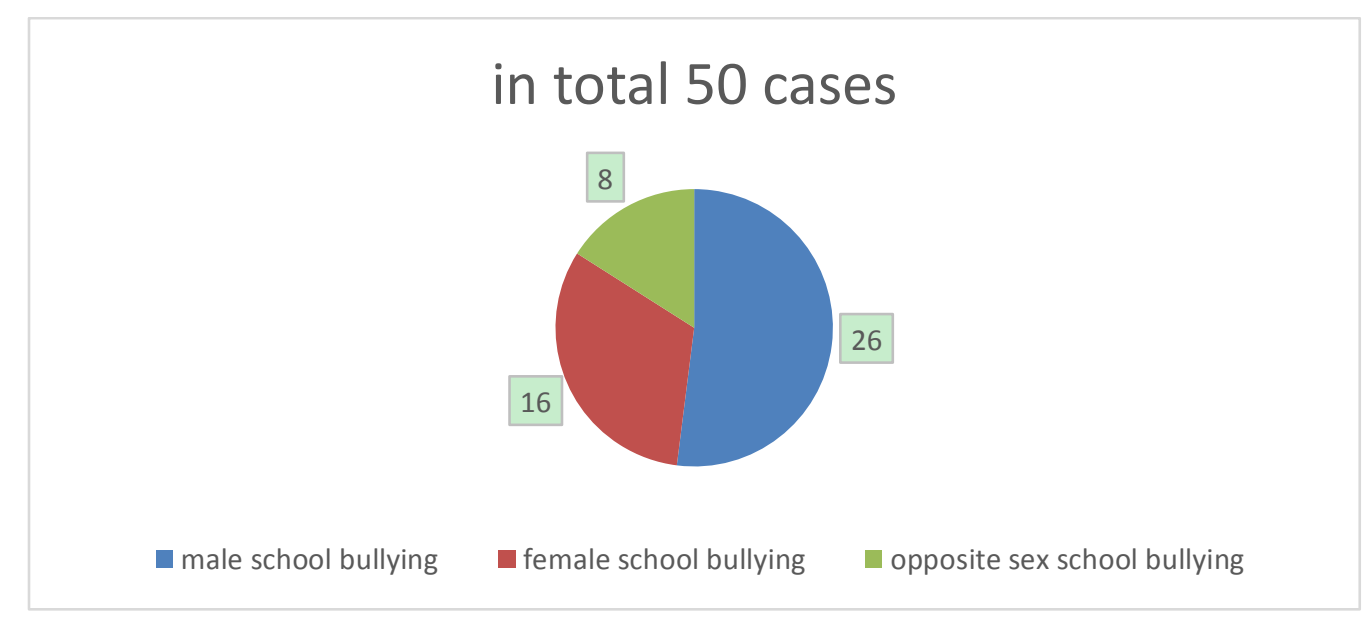

Figure 6. Gender structure of school bullying

It is worth noting that there are many differences between male school bullying and female school bullying. male school bullying is more often manifested as physical conflicts, usually involving robbery and extortion. While female school bullying is mainly manifested in marginalizing, swearing with bad words, cold violence or body abuse. When asked why they didn't bully girls, male perpetrators said they didn't want to bully weak girls that was not a man's behavior. Female perpetrators would say they are not interested in boys and the boys are not easy to be bullied. It's not surprising that there are almost no cases of boys being bullied by girls. In the cases of female students being bullied by boys, almost all the perpetrators carried out molesting, sexual insulting or other sexual bullying behaviors. The research shows that female students are more likely to be victims of school bullying. Among the 50 typical cases, the victims of 34 cases are female. But at the same time, female are also easy to become the perpetrators of school bullying. There are 26 cases in which the perpetrators include at least one female, accounting for $52 \%$, and 19 cases in which the perpetrators are just female, accounting for 38\%. (Shown in Figure 7) 


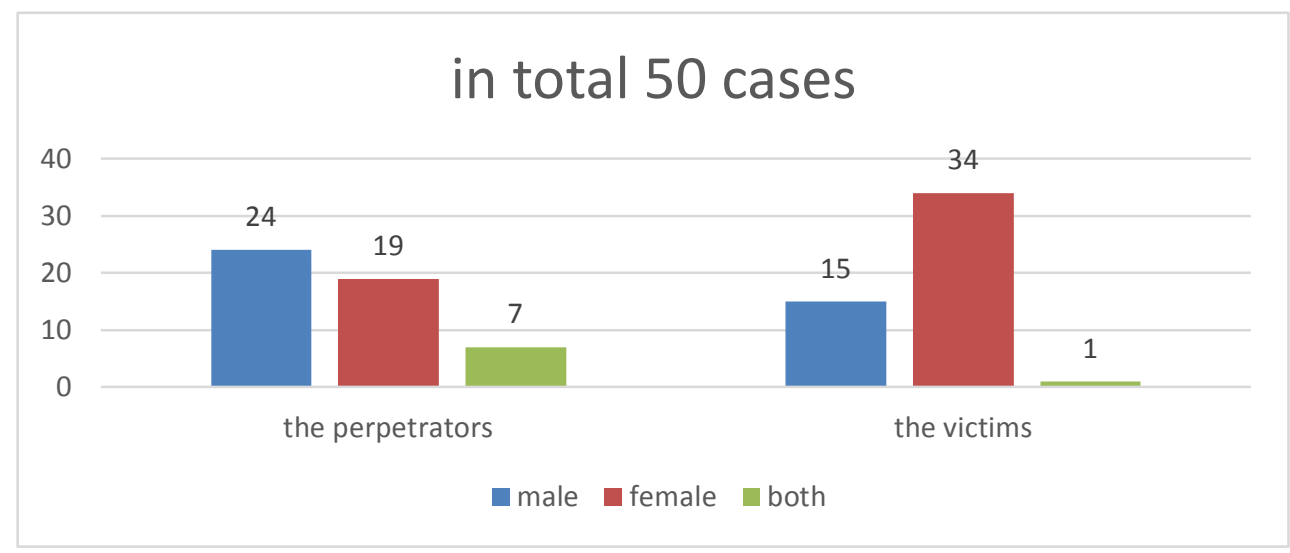

Figure 7. Gender of the perpetrators and the victims of school bullying

\section{Conclusion}

Through this survey, we found that most school bullying mainly occurred in senior high school and junior high school. In these cases, most of the perpetrators and the victims, who's thoughts are not really mature, are in the transition period from dependent personality to independent personality, and they have not yet established a complete outlook on life and values. They are very vulnerable to the influence of the surroundings, especially a bad family environment. Once psychological deviation occurs, they are easy to use extreme methods such as violence to solve problems. School bullying is a prelude and an important inducement for teenagers to commit crimes. If we do not take measures to stop and prevent school bullying in time, more and more teenagers will go to the road of crime.

From the current legal system of China, the laws related to the regulation of school bullying mainly include Criminal Law, Public Security Management Punishment Law, Prevention of Juvenile Delinquency Law and Juvenile Protection Law. However, the definition of the age of criminal responsibility in Criminal Law has become a short board to regulate campus bullying, that is, people under the age of 12 are not criminally responsible at all, while juveniles 12-16 years old bear criminal responsibility only when they commit the "eight felonies" according article 17 of Criminal Law, which leads to the deterrent and preventive functions of the criminal law. There is also the same problem in Public Security Management Punishment Law. The Prevention of Juvenile Delinquency Law defines juvenile school bullying as bad behavior, but points out that bad behavior is not enough for criminal punishment, which virtually reduces the deterrent to school bullying. As for Juvenile Protection Law of China, it aims to protect the healthy growth of minors, thus showing a legislative tendency of attaching importance to protection and belittling punishment. But from the actual situation, school bullying occurs more frequently in primary and secondary schools than in Colleges and universities. One of the important reasons is that the minds of primary and secondary school students are still immature, their awareness of social rules has not been formed, and the loss of legal regulation also provides soil for school bullying.

Nowadays, due to the increasingly gap between the rich and the poor in students' families, extreme poverty easily leads to students' inferiority complex, and affluence also makes some students develop a lot of inexplicable sense of superiority. In addition, the materialistic atmosphere of the whole society is becoming more and more serious, which leads to the serious utilitarian tendency of family education. In China, our educational philosophy has always taken examination result as the only benchmark to measure students' performance, while ignoring the cultivation of students' mental health and the establishment of their correct values. This is a serious drawback of our examination-oriented education. All these have resulted in the lack of a good educational environment for teenagers. In our time, the vulnerability of teenagers is more obvious than ever. The deviation of family education and school education make school bullying as a common phenomenon.

As a response, for one thing, we should improve the relevant laws to increase the punishment for campus bullying and to improve the legal protection for the victims. In addition, the government should also actively explore and establish the campus police system, so as to provide administrative protection for the victims of campus bullying outside the school. For another, our education authorities not only need to pay more attention to the safety of the campus, but also pay more attention to the quality education which aims to guide students to establish their correct values. The real purpose of school education should be to cultivate a responsible citizen, not just to cultivate a student with outstanding examination result as we always do. 


\section{References}

Huang, H. (2018). On the Countermeasures of School Bullying in High School. The Guide of Science \& Education, (32), 150 .

Li, M. (2020). Research on the Current Situation and Legal Regulation of Campus Bullying. Legal System and Society, (8), 133.

Li, S. (2019). Definition of School Bullying from the Perspective of Rule of Law: along with Discussions on the Relationship between School Bullying and School Violence. Journal of Dalian Maritime University (Social Science Edition), (18), 67.

Liu, D. (2018). On the Characteristics and Psychological Intervention Strategies of the Victims of School Bullying. Policy \& Scientific Consult, (12), 19.

Peng, C-J., Zhang, G-S., \& Chang, L-J. (2019). On the Current Situation of Non-physical Bullying in Primary School. Education Teaching Forum, (26), 60.

Shen, S-Z. (2019). On the Necessity of Making Anti-bullying Law in China. Legal System and Society, (13), 216.

Teng, F. (2017). On Legal Regulation Route of Campus Bullying Behavior. Administration and Law, (8), 77.

Yong, Q. (2019). Research on the Criminal Regulation of Juvenile Campus Bullying. Legality Vision, (29), 121.

Yu, Y., \& Shi, X-Q. (2019). The Characteristics and Social Prevention of Campus. Issues on Juvenile Crimes and Delinquency, (5), 9.

Zhang, W. (2017). On the Current Situation, Causes and Prevention of School Bullying. Journal of Guangxi Youth Leaders College, (27), 77-78.

Zhao, Q. (2020). On the Causes and Countermeasures of School Bullying. PR World, (4), 104.

\section{Copyrights}

Copyright for this article is retained by the author(s), with first publication rights granted to the journal.

This is an open-access article distributed under the terms and conditions of the Creative Commons Attribution license (http://creativecommons.org/licenses/by/4.0/). 